\title{
Probióticos: como uma microbiota intestinal saudável ajuda a combater infecções respiratórias virais agudas, similares à covid-19
}

\author{
Probiotics: how a healthy intestinal microbiota helps to combat acute viral respiratory \\ infections, similar to covid-19 \\ Probióticos: cómo un microbiot intestinal saludable ayuda a combatir las infecciones \\ respiratorias virales agudas, similar a covid-19
}

Diego Lisboa Rios ${ }^{1 *}$, Silvia de Siqueira Costa², Rodrigo César de Oliveira Sanches ${ }^{1}$, Vidyleison Neves Camargos ${ }^{1}$, César da Silva Santana Moura ${ }^{1}$, Thiago Araújo Andrade ${ }^{1}$, Pedro Gontijo Carneiro ${ }^{1}$, Cássio Siqueira Souza Cassiano $^{3}$, Welington Ribeiro Aquino Marques ${ }^{4}$, Patricia Costa Lima da Silva ${ }^{1}$.

\section{RESUMO}

Objetivo: Abordar os benefícios antivirais e imunológicos do uso de probióticos no combate de infecções respiratórias virais agudas, como as causadas pelo Coronavírus da Síndrome Respiratória Aguda Grave 2 (SARS-CoV-2). Revisão Bibliográfica: Em 2 de abril de 2020 o SARS-CoV-2, causador de infecções respiratórias virais agudas, já era uma pandemia com o número mundial de casos confirmados de 900.306 , em 206 países, com um total de mortes de 45.693. Em virtude da falta de vacinas e tratamentos disponíveis até o momento, o uso de alternativas como os probióticos, é uma estratégia viável baseada em comprovados resultados positivo. Probióticos são moduladores do sistema imunológico do hospedeiro, tendo ação antiviral por interferir na fixação, invasão e até na inibição da replicação viral. Resultados in vitro revelaram ainda, que produtos metabólicos da linhagem N4 de Lactobacillus plantarum apresentaram atividade significativa antiTGEV, um membro dos Coronavírus. Considerações finais: Apesar de ainda não existirem dados do efeito de probióticos em pacientes com a COVID-19, estudos sobre os efeitos de probióticos em infecções causados por outros vírus causadores de Infecção do trato respiratório superior (URI), sugerem potencial efeito benéfico na saúde da população em meio a pandemia.

Palavras-chave: Coronavírus, Probióticos, Imunomodulação, Pandemia, Antiviral.

\begin{abstract}
Objective: To address the antiviral and immunological benefits of using probiotics to combat acute viral respiratory infections, such as those caused by the Severe Acute Respiratory Syndrome Coronavirus 2 (SARSCoV-2). Bibliographic Review: As of April 2, 2020, SARS-CoV-2, which causes acute viral respiratoryinfections, was already a pandemic with a worldwide confirmed number of 900,306 cases in 206 countries, with a total death toll of 45,693 . Due to the lack of vaccines and treatments available to date, the use alternatives such as probiotics is a viable strategy based on proven positive results. Probiotics are modulators of the host's immune system, having antiviral action for interfering with fixation, invasion and even inhibition of viral replication. In vitro results also revealed that metabolic products of the N4 strain of Lactobacillus plantarum showed significant anti-TGEV activity, a member of the Coronaviruses. Final considerations: Although there
\end{abstract}

\footnotetext{
1 Universidade Federal de Minas Gerais (UFMG), Belo Horizonte - MG.

2 Universidade José do Rosário Vellano (UNIFENAS), Divinópolis - MG.

3 Universidade Federal de São João del-Rei (UFSJ), Divinópolis - MG.

${ }^{4}$ Universidade Federal de Ouro Preto (UFOP), Ouro Preto - MG.

*E-mail: lisboa.zootec@gmail.com
} 
are still no data on the effect of probiotics in patients with COVID-19, studies on the effects of probiotics on infections caused by other Upper respiratory tract infection (URI) causing viruses suggest a potential beneficial effect on the health of the population in the midst of a pandemic.

Keywords: Coronavirus, Probiotics, Immunomodulation, Pandemic, Antiviral.

\section{RESUMEN}

Objetivo: Abordar los beneficios antivirales e inmunológicos del uso de probióticos para combatir infecciones respiratorias virales agudas, como las causadas por coronavirus 2 del síndrome respiratorio agudo severo (SARS-CoV-2). Revisión bibliográfica: El 2 de abril de 2020, el SARS-CoV-2, que causa infecciones respiratorias virales agudas, ya era una pandemia con un número mundial confirmado de 900.306 casos en 206 países, con un total de 45,693 muertes. Debido a la falta de vacunas y tratamientos disponibles hasta la fecha, el uso de alternativas como los probióticos es una estrategia viable basada en resultados positivos probados. Los probióticos son moduladores del sistema inmunitario del huésped y tienen acción antiviral para interferir con la fijación, la invasión e incluso la inhibición de la replicación viral. Resultados in vitro también revelaron que productos metabólicos del linaje N4 de Lactobacillus plantarum mostraron importante actividad anti-TGEV, un miembro de Coronavirus. Consideraciones finales: Aunque todavía no hay datos sobre el efecto de los probióticos en pacientes con COVID-19, estudios sobre los efectos de probióticos en infecciones causadas por otros virus causantes de Infección del tracto respiratorio superior (URI), sugieren posible efecto beneficioso sobre la salud de la población en medio de una pandemia.

Palabras clave: Coronavirus, Probióticos, Inmunomodulación, Pandemia, Antiviral.

\section{INTRODUÇÃO}

Em dezembro de 2019, um surto contínuo de pneumonia associada a um novo coronavírus, chamado de Coronavirus da Síndrome Respiratória Aguda Grave 2 (SARS-CoV-2), foi relatado em Wuhan, província de Hubei, China. Nas semanas seguintes, infecções se espalharam pela China e outros países ao redor do mundo (HUANG C, et al., 2020).

Em 30 de janeiro de 2020, a Organização Mundial da Saúde (WHO) declarou o surto uma Emergência de Saúde Pública de Interesse Internacional (PHEIC). Em 12 de fevereiro de 2020, a WHO nomeou a doença causada pelo novo coronavírus como "Doença de Coronavírus 2019" (COVID-19) (WHO, 2020). Atualmente, sete coronavírus humanos já foram identificados e nomeados em ordem cronológica: Human Coronavirus 229E (HCoV-229E), Human Coronavirus OC43 (HCoV-OC43), SARS-CoV, Human Coronavirus NL63 (HCoVNL63, New Haven Coronavirus), Human Coronavirus HKU1, Middle East Respiratory Syndrome Coronavirus (MERS-CoV), SARS-CoV-2. O SARS-CoV-2 é completamente novo para o nosso sistema imunológico.

Antes do surto atual, não há evidências de exposição prévia de seres humanos ao SARS-CoV-2. A ausência dessa exposição prévia faz com que nosso sistema imunológico seja susceptível à infecção, causando um enorme número de casos com sintomatologia (tosse, febre, cansaço, dificuldade para respirar) ausente ou de moderada a grave. $O$ aumento da carga viral em hospedeiros imunodeficientes pode ser uma das razões pelas quais o vírus está se espalhando tão rapidamente pela população (PHAN LT, et al., 2020). O vírus é transmitido através de gotículas produzidas nas vias respiratórias das pessoas infectadas.

Ao espirrar ou tossir, essas gotículas podem ser inaladas ou atingir diretamente a boca, nariz ou olhos de pessoas em contato próximo. Estas gotículas podem também depositar-se em objetos e superfícies próximas que podem afetar quem nelas toque e leve a mão aos olhos, nariz ou boca, embora esta forma de transmissão seja menos comum (CHEN Y, et al., 2020).

Apesar dos esforços unidos dos sistemas de saúde pública, hospitais e da comunidade científica chinesas, que compartilharam prontamente a sequência genômica do novo vírus com o mundo, uma vacina pode ainda 
levar meses (WU D, et al., 2020). A demora no desenvolvimento de uma vacina faz necessário a busca por tratamentos eficazes para controlar e prevenir à infecção por SARS-CoV-2.

Dados clínicos iniciais mostraram potencial no tratamento de COVID-19 com esses três medicamentos e possíveis agentes: Cloroquina, um medicamento antimalárico; Inibidores de protease como o ritonavir, um medicamento anti-Vírus da imunodeficiência humana (HIV); Remdesivir, um medicamento antiviral usado anteriormente contra o Ebola. Atualmente, ensaios clínicos em larga escala estão em andamento na China e no mundo (WU D, et.al., 2020). Com a indisponibilidade de vacina ou de um tratamento clinicamente comprovado, as melhores estratégias de prevenção da infecção pelo SARS-CoV-2 são: realizar higiene pessoal ao lavar as mãos, isolamento social e reforçar o sistema imunológico (PHAN LT, et al., 2020).

Uma poderosa alternativa em meio a esta crise na saúde mundial é o uso de bactérias denominadas probióticas, capazes de interagir com nossa microbioma intestinal e, entre outros benefícios, reforçar 0 sistema imunológico, aumentar as respostas imunológicas e promover sinalização imunológica específica com relevância fisiológica (SANTADATI M, et al., 2015). Probióticos são definidos como organismos vivos com atribuição de promoção da saúde quando ingeridas em número adequado (FAO, et al., 2002). Diversos Lactobacillus spp. são usados amplamente como aditivo alimentar no tratamento de distúrbios gastrointestinais e ajuste do equilíbrio intestinal (STJERNQUIST-DESATNIK A, et al., 2000).

As bactérias ácido láticas (LABs) tem atividade antibacteriana e antiviral contra diversos vírus em hospedeiros humanos e animais. Experimentos já mostraram a inibição significativa do HIV (Vírus da Imunodeficiência Humana), H1N1 (Gripe Influenza Tipo A ou gripe suína), RSV (Vírus Sincicial Respiratório), TGEV (Coronavírus da gastroenterite transmissível) in vitro e redução da multiplicação viral in vivo, com níveis de interferon e outros fatores antivirais elevados (LEE DK, et al., 2015; CHAI W, et al., 2013; MAEDA N, et al., 2009).

Uma variedade de metabólitos, como plantaricina, exopolissacarídeos (EPS), ácido láctico, ácido acético, ácido gama-aminobutírico produzido por probióticos, são capazes de aumentar a imunidade corporal, antitumoral e antiviral (MERENSTEIN D, et al., 2010).

Diante disso, o presente artigo teve como objetivo apresentar uma revisão de literatura na qual sejam expostos os efeitos benéficos conhecidos do uso de probióticos e seu potencial antiviral e imunomodulador frente à alguns vírus causadores da Síndrome Respiratória Aguda Grave, similares ao SARS-CoV-2.

\section{REVISÃO BIBLIOGRÁFICA}

\section{Infecções respiratórias virais agudas}

As Infecções do trato respiratório superior (URI), como as causadas pela COVID-19, estão entre os problemas de saúde mais comuns em humanos (SANTADATI M, et al., 2015). Mesmo na ausência de pandemia, nos EUA, 25 milhões de consultas médicas são feitas por ano devido às URI. Em 2016, as doenças do sistema respiratório representaram 8,2\% de todas as mortes na União Europeia (HUANG C, et al., 2020).

Sabe-se que mais de 200 vírus causam infecções respiratórias em humanos. Os agentes causadores mais comuns são o Coronavírus, Vírus Sincicial Respiratório (RSV), Vírus Parainfluenza, Enterovírus (EV), Vírus Influenza e Adenovírus, sendo o principal o Rinovírus Humano (HRV). Os sintomas da URI surgem após um período de incubação que varia dependendo do agente causador (ARAUJO GV, 2015).

\section{Etiologia da COVID-19}

Os coronavírus são vírus conhecidos por causar infecções respiratórias e geralmente provocam resfriados leves. São associados à um terço dos casos registrados no mundo em épocas mais frias. O prefixo "corona", do latim coroa, deve-se à sua aparência de coroa solar devido a picos de proteínas em sua superfície medindo de 9 à 12 nm de comprimento (PHAN LT, et.al., 2020). Em relatório preliminar, a análise completa do genoma viral revela que o vírus compartilha $88 \%$ da identidade de sequência com dois coronavírus do tipo "Síndrome Respiratória Aguda Grave" (SARS) (bat-SL-CoVZC45 e bat-SL-CoVZXC21), derivados de morcegos. 
No entanto, o genoma é mais distante do Coronavírus da Síndrome Respiratória Aguda Grave (SARSCoV), 79\%, e do Coronavírus da Síndrome Respiratória do Oriente Médio (MERS-CoV), 50\%.

Por isso, foi chamado temporariamente de novo coronavírus 2019 (2019-nCoV) (ROUJIAN L, et al., 2020). O SARS-CoV-2 é um vírus de RNA de fita simples e polaridade positiva, com alta capacidade de mutação, e que por ter aproximadamente 29.903 nucleotídeos, é considerado um dos maiores vírus de RNA conhecido (CHEN Y, et al., 2020).

Existem quatro proteínas estruturais principais codificadas pelo genoma coronaviral, uma das quais é a proteína spike (S). Esta proteína transmembrana se liga ao receptor da enzima conversora de angiotensina 2 (ACE2) e medeia a fusão subsequente entre o envelope, contendo o RNA viral, e as membranas celulares do hospedeiro para, assim, facilitar a entrada na célula hospedeira (HUANG C, et al., 2020).

Em 11 de fevereiro de 2020, o Grupo de Estudos sobre Coronavírus (CSG) do Comitê Internacional de Taxonomia de Vírus (ICTV) finalmente o designou como Coronavírus da Síndrome Respiratória Aguda Grave 2 (SARS-CoV-2) com base na filogenia, taxonomia e prática estabelecida (CHEN Y, et al., 2020).

Logo depois, a WHO nomeou a doença causada por este coronavírus como Doença de Coronavírus 2019 (COVID-19). Com base nos dados atuais, o SARS-CoV-2 pode ter infectado inicialmente morcegos e transmitido aos seres humanos via pangolim, ou outros animais selvagens vendidos no mercado de frutos do mar de Huanan. A partir daí, a disseminação ocorreu via transmissão de humano para humano (PHAN LT, et al., 2020).

\section{Epidemiologia da "Doença de Coronavírus 2019"}

Evidências de grupos de familiares infectados e trabalhadores médicos confirmaram a presença de transmissão homem a homem por gotículas de saliva, contato e fômite. As estimativas atuais são de que 0 SARS-CoV-2 tem um período médio de incubação de 3 dias (faixa de 0 a 24 dias), com potencial transmissão assintomática (HUANG C, et al., 2020).

Em dezembro de 2019, apareceram os primeiros sintomas em pacientes já confirmados. No início a morbidade permaneceu baixa, mas atingiu um ponto de inflexão em meados de janeiro de 2020. Na presente data, 2 de abril de 2020, o número mundial de casos confirmados é de 900.306, em 206 países, com um total de mortes de 45.693 (WHO, 2020).

Apesar dos alarmantes números de mortes, a taxa de letalidade do novo vírus é em média 3,4\%, menor do que a da SARS ( $8 \%$ ) e da dengue $(3,8 \%)$, sendo que de $80 \%$ das pessoas que forem infectadas terão um quadro respiratório leve, muito semelhante a uma gripe.

Dos outros $20 \%$, o quadro pode evoluir com falta de ar e, numa parcela 5 a $10 \%$ deles, será necessária a assistência ventilatória, levando à internação hospitalar. Além disso, existem certos grupos chamados de risco. Na comparação da faixa etária, os grupos de maior vulnerabilidade são dos 70 à 79 anos $(8 \%)$ e mais de $80(14,8 \%)$.

Dentre os fatores que aumentam a letalidade, temos o câncer (6,2 vezes), hipertensão (6,7 vezes), doenças respiratórias crônicas ( 7 vezes), diabetes ( 8,1 vezes) e doenças cardiovasculares (11,7 vezes) (WU D, et al., 2020).

Com a indisponibilidade de vacinas e tratamentos comprovadamente eficazes, o controle da COVID-19 é a única alternativa neste momento.

Medidas eficazes de prevenção e controle devem incluir detecção, diagnóstico, tratamento dos casos graves em Unidade de Terapia Intensiva (UTI) e quarentena precoces, para bloquear a transmissão de pessoa para pessoa, além de reduzir infecções secundárias entre contatos próximos e profissionais de saúde (HUANG C, et al., 2020).

Um sistema imunológico preparado, forte e saudável, poderia ser a diferença no nível de gravidade dos sintomas da COVID-19, principalmente nas pessoas do grupo de risco (PHAN LT, et al., 2020). 


\section{Probióticos e seus efeitos comprovados na saúde}

Os probióticos devem atender aos seguintes critérios: devem sobreviver no trato gastrointestinal e serem capazes de proliferar no intestino; devem beneficiar o hospedeiro através do crescimento ou atividade; e não devem ser patogênicos ou tóxicos (YANG Y, et al., 2017). Características probióticas podem ser encontradas em diversos gêneros, espécies e linhagens de microrganismos. Embora evidências recentes sugerem que cada linhagem tenha alguns efeitos comuns à saúde, estas ainda apresentam muitos efeitos específicos na saúde (SANTADATI, et al., 2015).

Os organismos probióticos mais comuns são bactérias do gênero Bifidobacterium e Lactobacillus (STJERNQUIST-DESATNIK A, et al., 2000). Descobertas usando metanálises de probióticos de linhagens específicas, sugerem que os benefícios comuns à saúde são derivados do consumo de uma dose adequada de qualquer linhagem segura, já conhecida por ser um probiótico eficaz.

Por exemplo, uma metanálise usando diferentes linhagens em 10.351 pacientes, constatou que os probióticos tiveram um efeito positivo em oito doenças gastrointestinais em todas as espécies probióticas estudadas (YANG Y, et al., 2017).

Organização Mundial de Alergia (WAO) convocou um painel de diretrizes para desenvolver recomendações baseadas em evidências científicas para o uso de probióticos na prevenção de alergias (YANG Y, et al., 2017).

Existem ainda evidências para apoiar o uso de probióticos em várias condições: prevenção de gastroenterite aguda, enterocolite necrosante, diarréia associada à antibióticos, constipação, síndrome do intestino irritável, doenças inflamatórias intestinais, intolerância à lactose, alergias, eczema atópico, certos tipos de câncer, doenças hepáticas, hiperlipidemia, infecção por Helicobacter pylori, infecções do trato geniturinário e saúde bucal (YANG Y, et al., 2017).

A Associação Européia de Gastroenterologia, Hepatologia e Nutrição Pediátrica (ESPGHAN) também estabeleceu recomendações para o uso de probióticos na prevenção e tratamento de gastroenterite aguda em crianças (TAPIOVAARA L, et al., 2014).

Além disso, metanálise de linhagem probiótica específica concluiu que o Lactobacillus rhamnosus GG (L. GG) era eficaz na prevenção da diarréia associada à antibióticos em crianças e adultos tratados com antibióticos por qualquer motivo (SWANLJUNG E, et al., 2015).

\section{Mecanismos de ação - Probióticos}

Os mecanismos de ação dos probióticos em infecções virais e bacterianas ainda não são completamente compreendidos. Linhagens específicas, exibem potenciais probióticos específicos, reforçando a integridade do epitélio intestinal e regular componentes do sistema imunológico.

$\mathrm{Na}$ regulação de respostas imunes complexas, o trato gastrointestinal da cavidade oral ao reto, é considerado a maior interface imune do hospedeiro com o meio ambiente.

Os potenciais mecanismos são estudados principalmente no epitélio gastrointestinal. Os potenciais mecanismos de ação no trato respiratório permanecem desconhecidos, e mecanismos semelhantes aos do epitélio intestinal podem existir, mas o tópico precisa ser mais estudado (YANG Y, et al., 2017).

Alguns mecanismos postulados de ação probiótica na defesa epitelial intestinal são apresentados na (Figura 1).

É possível que bactérias probióticas possam se ligar a um vírus invasor, inibindo assim a ligação do vírus ao receptor da célula hospedeira (SALMINEN S, et al., 2010).

As LABs podem exercer atividade antiviral das seguintes maneiras: interação direta como um mecanismo de adsorção ou captura; estimulação do sistema imunológico por interleucina, células "assassinas" naturais, atividade de resposta imune celular do tipo Th1 e produção de IgA; produção de agentes antivirais (por exemplo, peróxido de hidrogênio, ácido lático e bacteriocinas) (ARAUJO GV, 2015). 
Figura 1 - Possíveis mecanismos pelos quais as bactérias probióticas modulam as respostas de defesa intestinal.

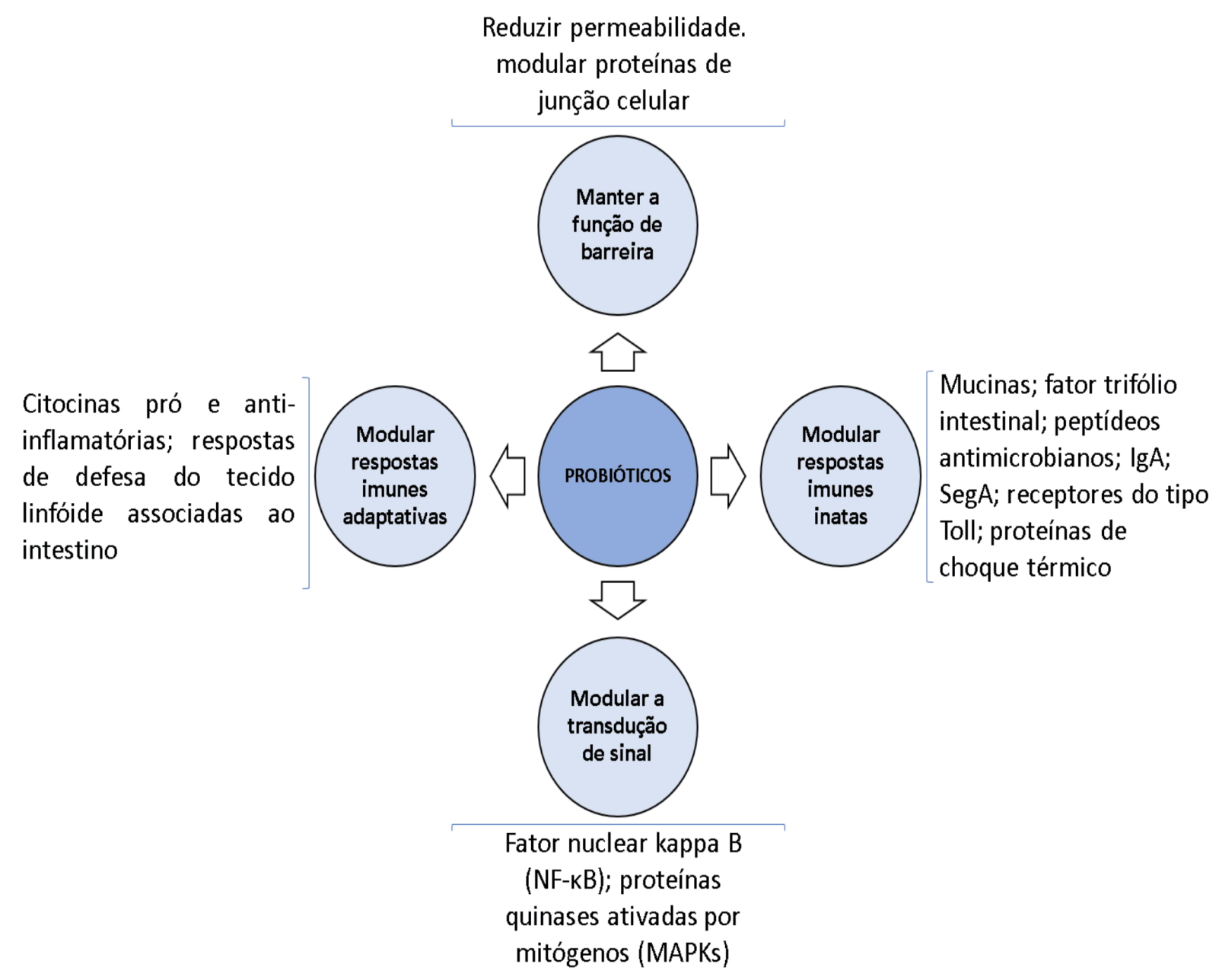

Fonte: Rios DL, et al., 2020; dados extraídos de Salminen S, et al., 2010; Araujo GV, 2015; Yang Y, et al., 2017.

\section{Microbiota do trato respiratório e suas implicações na saúde}

A microbiota nasofaríngea e adenóide (MNA) é um sistema interativo complexo, abrigando uma grande variedade de bactérias e vírus. Em crianças, observou-se que a MNA mudava de acordo com a estação, e as proporções de táxons mudavam com o uso de antibióticos. Sendo ainda demonstrado que os vírus respiratórios realizam alterações na adesão bacteriana, colonização e mecanismos imunológicos, na nasofaringe (YANG Y, et al., 2017). A MNA pode afetar a vulnerabilidade dos indivíduos a infecções respiratórias. Um estudo demonstrou que crianças pequenas apresentavam pequena variedade de táxons e altas contagens totais de bactérias em sua nasofaringe. Ao contrário de seus pais, que apresentavam muita variedade de táxons e contagem bacteriana baixa. Esse achado sugere que uma maior variedade de MNA poderia proteger o indivíduo contra a URI (YANG Y, et al., 2017).

É possível ainda que a maturação da comunidade microbiana associada ao hospedeiro ocorra de maneira semelhante na área nasofaríngea e no intestino. Curiosamente, o desenvolvimento da MNA já foi estudado em 60 crianças saudáveis, e certos padrões de microbiota foram associados a reduções nos episódios de URI relatados pelos pais. Diante disto, os cientistas começaram a investigar o efeito da adição de bactérias benéficas na microbiota intestinal e respiratória de adultos e crianças (SANTADATI M, et al., 2015). 


\section{Colonização do trato respiratório com probióticos}

A colonização do epitélio intestinal por probióticos têm sido extensivamente estudadas (ALANDER M, et al., 1999). Experimentos já identificaram que a adesão na mucosa, apesar de importante, é incorretamente ensinada como essencial para os mecanismos de defesa imunológica e não imune na mucosa. Por exemplo, probióticos não colonizadores, como Lactobacillus casei, podem exercer suas funções de maneira transitória ou influenciar a comunidade microbiana existente (MERENSTEIN D, et al., 2010). Já a colonização do epitélio do sistema respiratório com probióticos específicos ou bactérias do ácido lático, ainda não é muito bem conhecida. Em um estudo piloto, foi observada a presença do probiótico Lactobacillus plantarum DSM9843 a partir da superfície tonsilar de 6 indivíduos no prazo de até oito horas após o consumo por via oral de mingau de aveia fermentado e enriquecido com este probiótico, sugerindo que a cepa pode possuir a capacidade de adesão às células tonsilares (STJERNQUIST-DESATNIK A, et al., 2000).

Em outro estudo populacional da microbiota, foi investigado a recuperação de Streptococcus salivarius K12 na nasofaringe e na cavidade oral após a ingestão oral. Neste estudo, uma das 19 culturas nasofaríngeas foi relatada positiva para o probiótico e foi recuperada de três adenóides, das sete examinadas (POWER DA, et al., 2008). Ainda, um experimento tratou 20 adultos com Streptococcus salivarius 24 SMBc intranasal por três dias. Os resultados mostraram que $95 \%$ dos indivíduos foram colonizados na nasofaringe com o probiótico pelo menos quatro horas após a administração do spray, a colonização persistiu por pelo menos seis dias em 55\% dos indivíduos (SANTADATI M, et al., 2015).

A recuperação tonsilar de Lactobacillus rhamnousus (GG), após consumo oral foi estudada em 57 adultos jovens por estudo controlado com placebo e randomizado. L. GG foi recuperado em $40 \%$ das amostras tonsilares dos grupos L. GG e em 30\% das amostras dos grupos placebo (KUMPU M, et al., 2013). O L. GG também foi recuperado do tecido adenóide de crianças que consumiram o probiótico por via oral em um experimento randomizado, duplo-cego. Nestes casos, todos os indivíduos que consumiram L. GG apresentaram a bactéria na adenóide, bem como $76 \%$ das amostras dos grupos placebo foram positivas (SWANLJUNG E, et al., 2015). Vinte e cinco amostras de efusão do Fluido do Ouvido Médio (MEF) da mesma população de estudo foram estudadas em outro trabalho. Neste, $21 \%$ dos grupos tratados com L.GG, mantiveram a permanência deste probiótico. No entanto, apenas $7 \%$ dos grupos placebo apresentaram L.GG no MEF (TAPIOVAARA L, et al., 2014). A descrição dos estudos, que investigaram a colonização do trato respiratório com probióticos, são apresentados na (Tabela 1). 
Tabela 1 - Características dos estudos anteriores que investigaram a colonização do trato respiratório com probióticos; RDBPC = ensaio clínico prospectivo, randomizado, controlado por placebo; UFC = unidade formadora de colônia.

\begin{tabular}{|c|c|c|c|c|}
\hline Temas & $\begin{array}{l}\text { Metodologia e } \\
\text { duração }\end{array}$ & $\begin{array}{l}\text { Suplementação } \\
\text { probiótica }\end{array}$ & $\begin{array}{l}\text { Principais } \\
\text { conclusões }\end{array}$ & Referência \\
\hline $\begin{array}{c}\text { Voluntários } \\
\text { saudáveis, com } \\
\text { idade média de } 38 \\
\text { anos }(n=6) \text {. }\end{array}$ & $\begin{array}{c}\text { Amostras de } \\
\text { zaragatoa de } \\
\text { amígdalas, após } \\
\text { administração única } \\
\text { por via oral. }\end{array}$ & $\begin{array}{l}\text { L. plantarum } \\
\text { UFC) }\end{array}$ & $\begin{array}{c}\text { A colonização } \\
\text { permaneceu por } 8 \\
\text { horas. }\end{array}$ & $\begin{array}{c}\text { STJERNQUIST- } \\
\text { DESATNIK A, et } \\
\text { al., 2000. }\end{array}$ \\
\hline $\begin{array}{c}\text { Crianças agendadas } \\
\text { para timpanostomia, } \\
\text { com idade entre } 0,5 \\
\text { e } 5 \text { anos }(n=19)\end{array}$ & $\begin{array}{l}\text { Amostras de swab } \\
\text { da língua e } \\
\text { nasofaringe, } \\
10 \text { dias. }\end{array}$ & $\begin{array}{c}\text { S. salivarius K12 (1.7 } \\
\times 10^{10} \text { UFC). }\end{array}$ & $33 \%$ colonizados. & $\begin{array}{l}\text { POWER DA, et } \\
\text { al., } 2008 .\end{array}$ \\
\hline $\begin{array}{c}\text { Jovens agendados } \\
\text { para } \\
\text { amigdalectomia, } \\
\text { com idade média de } \\
24,5 \text { anos }(\mathrm{n}=57) \text {. }\end{array}$ & $\begin{array}{c}\text { Amostras de } \\
\text { tecido da } \\
\text { amígdala RDBPC, } 3 \\
\text { semanas. }\end{array}$ & $\begin{array}{l}\text { L.GG (2x1010 UFC) } \\
\text { ou multiespécies } \\
\text { L.GG, Lc705, PJS, } \\
\text { BB12. }\end{array}$ & $\begin{array}{l}\text { 30-40\% de } \\
\text { colonizados em } \\
\text { diferentes grupos } \\
\text { de intervenção. }\end{array}$ & $\begin{array}{l}\text { KUMPU M, al., } \\
2013 .\end{array}$ \\
\hline $\begin{array}{c}\text { Adultos saudáveis } \\
\text { com idade entre } \\
30 \text { e } 54 \text { anos }(n= \\
20) \text {. }\end{array}$ & $\begin{array}{c}\text { Spray nasal, } \\
\text { zaragatoas } \\
\text { rinofaríngeas, } 3 \text { dias. }\end{array}$ & $\begin{array}{c}\text { S. salivarius } 24 S M B C \\
\left(8 \times 10^{9} \text { ufc }\right) .\end{array}$ & $\begin{array}{c}95 \% \text { colonizados, } \\
55 \% \\
\text { permaneceram } \\
\text { por seis dias. }\end{array}$ & $\begin{array}{l}\text { SANTAGATI M, } \\
\text { et al., } 2015 .\end{array}$ \\
\hline $\begin{array}{l}\text { Crianças agendadas } \\
\text { para adenotomia, } \\
\text { com média de idade } \\
\text { de } 37,8 \text { meses ( } n= \\
31 \text { ). }\end{array}$ & $\begin{array}{c}\text { Amostras de } \\
\text { adenóide RDBPC, } \\
3 \text { semanas. }\end{array}$ & $\begin{array}{c}\text { L. GG } \\
\left(8-9 \times 10^{9} \text { UFC }\right) \times 2 .\end{array}$ & $\begin{array}{l}100 \% \text { colonizado } \\
\text { no grupo L. GG, } \\
76 \% \text { no grupo } \\
\text { placebo. }\end{array}$ & $\begin{array}{l}\text { SWANLJUNG E, } \\
\text { et al., } 2015 .\end{array}$ \\
\hline $\begin{array}{l}\text { Crianças agendadas } \\
\text { para timpanostomia, } \\
\text { com idade média de } \\
31 \text { meses }(n=13)\end{array}$ & $\begin{array}{c}\text { Amostras RDBPC, } \\
\text { MEE, } \\
3 \text { semanas. }\end{array}$ & $\begin{array}{c}\text { L. GG } \\
\left(8-9 \times 10^{9} \text { UFC) } \times 2 .\right.\end{array}$ & $\begin{array}{c}21 \% \text { colonizados } \\
\text { no grupo L.GG, } \\
7 \% \text { no grupo } \\
\text { placebo. }\end{array}$ & $\begin{array}{l}\text { TAPIOVAARA L, } \\
\text { et al., } 2014 .\end{array}$ \\
\hline
\end{tabular}

Fonte: Rios DL, et al., 2020.

Identificada a colonização por bactérias probióticas benéficas ao organismo, investigou-se o impacto destas na proteção e imunomodulação do hospedeiro diante de infecções virais.

\section{Efeitos clínicos dos probióticos no trato respiratório}

A prevenção de infecções respiratórias pelo uso de probióticos vem sendo estudada por vários experimentos. Por exemplo, L.GG sozinho ou em combinação com outros probióticos demonstrou reduzir a incidência ou o risco de URI em crianças (HATAKKA K, et al., 2001). Uma revisão sistemática recente encontrou um resultado favorável ao uso de probióticos na redução dos episódios de novas URI em crianças (ARAUJO GV, 2015).

No Banco de Dados Cochrane de Revisões Sistemáticas (CDSR), encontra-se trabalho sobre o uso de probióticos em URI, no qual categorizou 13 ensaios clínicos randomizados com participantes em várias faixas etárias, (Tabela 2).

Verificou-se que os probióticos eram melhores que o placebo na redução do número de indivíduos que experimentaram URI, havendo ainda redução na duração média desta, no número de prescrições de antibióticos e nas faltas escolares relacionadas ao frio (HAO Q, et al., 2015). 
Tabela 2 - Características dos estudos controlados randomizados; $\mathrm{RD}=$ randomizado, $\mathrm{B}=$ controlado por placebo, $\mathrm{P}=$ prospectivo, $\mathrm{C}=$ ensaio clínico.

\begin{tabular}{|c|c|c|c|c|}
\hline Temas & $\begin{array}{l}\text { Metodologia e } \\
\text { duração }\end{array}$ & Suplementação probiótica & $\begin{array}{l}\text { Principais conclusões: } \\
\text { Probiótico vs. placebo }\end{array}$ & Referência \\
\hline $\begin{array}{l}\text { Adultos saudáveis com } \\
\text { idade entre } 18 \text { e } 65 \text { anos }(n=318) \text {. }\end{array}$ & $\begin{array}{l}\text { RDBPC, } 3 \\
\text { meses. }\end{array}$ & 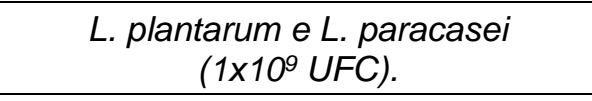 & $\begin{array}{l}\text { Incidência de episódios de resfriado comum } \downarrow \\
\text { Número de dias com sintomas respiratórios } \downarrow\end{array}$ & $\begin{array}{l}\text { BERGGREN A, et al. } \\
2011 .\end{array}$ \\
\hline Creches de 1 a 5 anos $(n=398)$. & RDBC, 3 meses. & L. rhamnosus HN001 (1010 UFC). & $\begin{array}{c}\text { Número e duração de URI } \leftrightarrow \\
\text { Nível de IgA secretora } \uparrow \\
\end{array}$ & $\begin{array}{l}\text { CACERES P, et al. } \\
2010 .\end{array}$ \\
\hline $\begin{array}{l}\text { Voluntários mais velhos em creches } \\
\qquad(n=154)\end{array}$ & $\begin{array}{l}\text { RDBPC, } 5 \\
\text { meses. }\end{array}$ & $\begin{array}{l}\text { L. casei estirpe Shirota } \\
\left(4 \times 10^{10} \text { UFC). }\right.\end{array}$ & $\begin{array}{c}\text { Número de URI aguda e escore de sintomas } \\
\qquad \leftrightarrow\end{array}$ & FUJITA R, et al. 2013. \\
\hline $\begin{array}{c}\text { Creches com idade entre } 13 \text { e } 86 \\
\text { meses }(n=281)\end{array}$ & $\begin{array}{l}\text { RDBPC, } 3 \\
\text { meses. }\end{array}$ & L. rhamnosus GG (109 UFC). & $\begin{array}{c}\text { Risco de URI } \downarrow \\
\text { Dias com sintomas respiratórios } \downarrow\end{array}$ & HOJSAK I, et al. 2010a. \\
\hline $\begin{array}{l}\text { Hospitalizado em pediatria, acima de } \\
1 \text { ano }(\mathrm{n}=742) .\end{array}$ & $\begin{array}{l}\text { RDBPC, tempo } \\
\text { de internação. }\end{array}$ & L. rhamnosus GG (109 UFC). & $\begin{array}{c}\text { Risco de URI } \downarrow \\
\text { Episódios de URI> } 3 \text { dias } \downarrow\end{array}$ & HOJSAK I, et al. 2010b. \\
\hline $\begin{array}{l}\text { Voluntários saudáveis com idades } \\
\text { entre } 69 \text { e } 80 \text { anos }(n=60)\end{array}$ & $\begin{array}{l}\text { RPC, } 2 \text { ou } 3 \\
\text { meses. }\end{array}$ & $\begin{array}{c}\text { L. bulgaricus }\left(1,8-3,2 \times 10^{10} \text { UFC) }\right. \\
\text { e S. thermophilus }\left(5,7-7,9 \times 10^{10}\right. \\
\text { UFC). }\end{array}$ & $\begin{array}{c}\text { Risco de URI } \downarrow \\
\text { Atividade natural de células assassinas } \uparrow\end{array}$ & MAKINO S, et al. 2010. \\
\hline $\begin{array}{c}\text { Creche saudável ou crianças em } \\
\text { idade escolar de } \\
3-6 \text { anos }(n=638) .\end{array}$ & $\begin{array}{l}\text { RDBPC, } 3 \\
\text { meses. }\end{array}$ & $\begin{array}{c}\text { L. casei }\left(2 \times 10^{10}\right. \\
\text { UFC), S.thermophiles e } L . \\
\text { bulgaricus }\left(10^{9} \text { UFC) }\right.\end{array}$ & Incidência de doenças infecciosas comuns $\downarrow$ & $\begin{array}{l}\text { MERENSTEIN D, et al. } \\
2010 .\end{array}$ \\
\hline $\begin{array}{l}\text { Bebês que necessitam de fórmula } \\
\text { com idade entre } 0-2 \text { meses }(n=81) \text {. }\end{array}$ & $\begin{array}{l}\text { RDBPC, } 12 \\
\text { meses. }\end{array}$ & $\begin{array}{l}\text { L. rhamnosus e B. lactis BB-12 } \\
\text { (1x1010 UFC). }\end{array}$ & $\begin{array}{c}\text { Risco de URI } \downarrow \\
\text { Risco de OMA e antibióticos } \downarrow\end{array}$ & $\begin{array}{l}\text { RAUTAVA S, et al. } \\
2009 .\end{array}$ \\
\hline $\begin{array}{l}\text { Crianças saudáveis de } \\
8 \text { a } 13 \text { anos }(n=80)\end{array}$ & $\begin{array}{l}\text { RDBPC, } 3 \\
\text { meses. }\end{array}$ & $\begin{array}{l}\text { L. acidophilus e B. bifidum (1X109 } \\
\text { UFC). }\end{array}$ & $\begin{array}{c}\text { Sintomas da URI } \downarrow \\
\text { Ausências na escola relacionadas à URI } \downarrow\end{array}$ & $\begin{array}{l}\text { RERKSUPPAPHOL S, } \\
\text { et al. } 2012 .\end{array}$ \\
\hline Crianças de 6 a 25 meses $(n=100)$ & RPC, 3 meses. & $\begin{array}{l}\text { L. acidophilus e L. casei (109- } 1010 \\
\text { UFC). }\end{array}$ & Episódios de infecções do trato respiratório $\downarrow$ & RÍO ME, et al. 2002. \\
\hline $\begin{array}{l}\text { Crianças em idade escolar de } \\
3 \text { a } 12 \text { anos }(n=251) .\end{array}$ & $\begin{array}{l}\text { RDBPC, } 5 \\
\text { meses. }\end{array}$ & L. casei. & Duração das infecções respiratórias inferiores & SANZ JM, et al. 2006. \\
\hline $\begin{array}{l}\text { Estudantes universitários de } 18 \text { a } 24 \\
\text { anos }(n=198)\end{array}$ & $\begin{array}{l}\text { RDBPC, } 3 \\
\text { meses. }\end{array}$ & $\begin{array}{l}\text { L. rhamnosus GG e } B \text {. } \\
\text { animalisssp. lactis BB-12. }\end{array}$ & $\begin{array}{c}\text { Duração ou URI } \downarrow \\
\text { Média da pontuação da gravidade } \downarrow \\
\text { Dias de aula perdidos } \downarrow\end{array}$ & SMITH TJ, et al. 2013. \\
\hline $\begin{array}{l}\text { Adultos saudáveis, idade média } 38 \pm \\
\qquad 13(n=479)\end{array}$ & $\begin{array}{l}\text { RDBPC, } 8,5 \\
\text { meses. }\end{array}$ & $\begin{array}{l}\text { L. gasseri, } B \text {. longum e } B \text {. } \\
\text { bifidum ( } 5 \times 107 \text { ufc). }\end{array}$ & $\begin{array}{c}\text { Duração da URI } \downarrow \\
\text { Escore total de sintomas } \downarrow \\
\text { Dias com febre durante a URI } \downarrow\end{array}$ & $\begin{array}{l}\text { DE VRESE M, et al. } \\
2005 .\end{array}$ \\
\hline
\end{tabular}

Fonte: Rios DL, et al., 2020. 
Uma metanálise com estudos randomizados e controlados por placebo, indica que o L. GG é capaz de reduzir a incidência de Otite Média Aguda (OMA), prescrições de antibióticos e o risco de URI em crianças (LIU S, et al., 2013). No entanto, em crianças propensas a otite com colonização por patógenos nasofaríngeos, o L. GG não reduziu a ocorrência de OMA (HATAKKA K, et al., 2007).

Novo modelo de tratamento da bacterioterapia intranasal por spray com Streptococcus sanguinis e L.GG, mostrou-se eficaz na diminuição do MEF em crianças com prolongada Otite Média com Efusão (OME). A recuperação de ambos os probióticos foi estatisticamente significante (SKOVBJERG S, et al., 2009). Em crianças propensas a otite, o consumo de L. GG, Lc705, BB99 e PJS reduziu significativamente o número de amostras nasofaríngeas positivas de bocavírus humano (LEHTORANTA L, et al., 2012). Além disso, o L. GG foi recuperado do tecido epitelial das amígdalas, após o consumo oral e apresentando ainda, adesão prolongada (acima de 4 semanas) (KUMPU M, et al., 2013). Experimento in vitro indicou que L. GG é capaz de inibir a aderência do Streptococcus pneumoniae às células epiteliais humanas (WONG SS, et al., 2000).

Dois estudos de revisão sugeriram que algumas linhagens de probióticos específicas interagem com patógenos, e têm o potencial de reduzir a colonização destes na nasofaringe, reduzindo potencialmente a OMA e a URI (SALMINEN S, et al., 2010).

\section{Latobacillus plantarum possui efeito antiviral in vitro contra Coronavírus}

O TGEV pertence à família Coronaviridae, gênero Alphacoronavirus, espécie Alphacoronavirus 1, sendo o SARS-COV-2, do gênero Betacoronavirus, espécie Sarbecovirus. O TGEV causa problemas respiratórios e diarréia graves (YANG Y, et al., 2017). Yang Y, et al., (2017); demonstraram in vitro que o mecanismo antiviral do probiótico Lactobacillus plantarum inclui a colonização do epitélio, impedindo estereotipicamente a adesão do TGEV à superfície. Ainda ocorre a ligação entre receptores do probiótico (como pAPN) e o vírus, formando complexos. Não obstante, os probióticos e seus metabólitos também podem interferir indiretamente com 0 vírus, alterando o estado das células, além de estimular a imunidade inata ou adaptativa.

A Cromatografia gasosa acoplada à espectrometria de massas (GC-MS) revelou que os sobrenadantes do probiótico podem conter aproximadamente 123 compostos, sendo mais alta a proporção de moléculas de açúcar. Já a análise por método Methylthiazolyl-diphenyl-Tetrazolium Bromide (MTT) indicou que a principal substância antiviral é o EPS. A surfactina, outro metabólito produzido por Lactobacillus plantarum, têm atividade antiviral contra o TGEV. Ela entra nas células IPEC-J2 absorvendo partículas de vírus e bloqueando a ligação viral por inibição competitiva. Metabólitos dos probióticos ainda poderiam ter um efeito inibitório direto na proliferação do vírus, como entrar diretamente no núcleo capsídeo para destruir o RNA viral, afetando a montagem das partículas do vírus e produzindo compostos tóxicos ao vírus.

\section{CONSIDERAÇÕES FINAIS}

Esta revisão propõe-se elucidar a importância do reforço do sistema imunológico pelo uso de probióticos, como estratégia válida frente a (URI), similares à COVID-19. Salientamos ainda, que a manutenção de uma diversidade microbiana intestinal saudável e, por consequência, da imunidade do hospedeiro, tem impacto ainda mais acentuado nos grupos de risco, por estes já estarem em situação de maior vulnerabilidade imunológica. Apesar de ainda não existirem dados do efeito de probióticos em pacientes infectados com o SARS-CoV-2, estudos sobre os efeitos de probióticos em infecções causados por outros vírus causadores de URI, sugerem potencial efeito benéfico na saúde da população em meio a pandemia viral.

\section{REFERÊNCIAS}

1. ALANDER M, et al. Persistence of colonization of human colonic mucosa by a probiotic strain, Lactobacillus rhamnosus GG, after oral consumption. Appl.Environ.Microbiol, 1999; 65: 351-354.

2. ARAUJO GV, et al. Probiotics for the treatment of upper and lower respiratory-tract infections in children: systematic review based on randomized clinical trials. J.Pediatr.(Rio J), 2015; 91: 413-427.

3. BERGGREN A, et al. Randomised, double-blind and placebo-controlled study using new probiotic lactobacilli for strengthening the body immune defence against viral infections. Eur.J.Nutr, 2011; 50: 203-210. 
4. CACERES $P$, et al. Effects of HN001 on acute respiratory infections and intestinal secretory IgA in children. 2010; 5: 353-362.

5. CHAl W, et al. Antiviral efects of a probiotic enterococcus faecium, strain against transmissible gastroenteritis coronavirus. Archives of Virology, 2013; 158: 799-807.

6. CHEN Y, et al. Emerging coronaviruses: Genome structure, replication, and pathogenesis. J Med Virol, 2020; Apr;92(4):418-423. doi: 10.1002/jmv.25681.

7. DE VRESE M, et al. Effect of Lactobacillus gasseri PA 16/8, Bifidobacterium longum SP 07/3, B. bifidum MF 20/5 on common cold episodes: a double blind, randomized, controlled trial. Clin.Nutr, 2005; 24: 481-491.

8. FAO. Report of a Joint FAO/WHO Working Group on Drafting Guidelines for the Evaluation of Probiotics in Food. London, Ontario, Canada, 2002.

9. FUJITA R, et al. Decreased duration of acute upper respiratory tract infections with daily intake of fermented milk: a multicenter, double-blinded, randomized comparative study in users of day care facilities for the elderly population. Am.J.Infect.Control, 2013; 41: 1231-1235.

10. HAO Q, et al. Probiotics for preventing acute upper respiratory tract infections. Cochrane Database Syst.Rev, 2015; 2: CD006895.

11. HATAKKA K, et al. Effect of long term consumption of probiotic milk on infections in children attending day care centres: double blind, randomised trial. 2001; BMJ 322: 1327.

12. HATAKKA K, et al. Treatment of acute otitis media with probiotics in otitis-prone children-a double-blind, placebocontrolled randomised study. ClinNutr, 2007; 26: 314-321.

13. HOJSAK I, et al. Lactobacillus GG in the prevention of gastrointestinal and respiratory tract infections in children who attend day care centers: a randomized, double-blind, placebo-controlled trial. ClinNutr, 2010; 29: 312-316.

14. HOJSAK I, et al. Lactobacillus GG in the prevention of nosocomial gastrointestinal and respiratory tract infections. Pediatrics, 2010; 125: e1171-1177.

15. HUANG C, et al. Clinical features of patients infected with 2019 novel coronavirus in Wuhan, China. pii: S01406736(20)30183-5, 2020; doi: 10.1016/S0140-6736(20)30183-5.

16. KUMPU M, et al. Recovery of probiotic Lactobacillus rhamnosus GG in tonsil tissue after oral administration: randomised, placebo-controlled, double-blind clinical trial. Br.J. Nutr, 2013; 109: 2240-2246.

17. LEE DK, et al. Probiotic bacteria, B. longum and L. acidophilus inhibit infection by rotavirus in vitro and decrease the duration of diarrhea in pediatric patients. Clinics \& Research in Hepatology \& Gastroenterology, 2015; 39: $237-244$.

18. LEHTORANTA L, et al. Human bocavirus in the nasopharynx of otitis-prone children. Int J Pediatr Otorhinolaryngol, 2012; 76: 206-211.

19. LIU S, et al. Lactobacillus rhamnosus GG supplementation for preventing respiratory infections in children: a metaanalysis of randomized, placebo-controlled trials. Indian Pediatr, 2013; 50: 377-381.

20. MAEDA N, et al. Oral administration of heat-killed lactobacillus plantarum I-137 enhances protection against influenza virus infection by stimulation of type i interferon production in mice. International Immunopharmacology, 2009; 9: 11 22.

21. MAKINO S, et al. Reducing the risk of infection in the elderly by dietary intake of yoghurt fermented with Lactobacillus delbrueckii ssp. bulgaricus OLL1073R-1. Br J Nutr, 2010; 104: 998-1006.

22. MERENSTEIN D, et al. Use of a fermented dairy probiotic drink containing Lactobacillus casei (DN-114 001) to decrease the rate of illness in kids: the DRINK study. A patient-oriented, double-blind, cluster-randomized, placebocontrolled, clinical trial. Eur.J.Clin.Nutr, 2010; 64: 669-677.

23. PHAN LT, et al. Importation and human-to-human transmission of a novel coronavirus in Vietnam. NEJM. January 28, 2020. doi: 10.1056/NEJMc2001272.

24. POWER DA, et al. Preliminary investigations of the colonisation of upper respiratory tract tissues of infants using a paediatric formulation of the oral probiotic Streptococcus salivarius K12. Eur.J.Clin.Microbiol.Infect.Dis, 2008; 27: 1261-1263.

25. RAUTAVA S, et al. Specific probiotics in reducing the risk of acute infections in infancy--a randomised, double-blind, placebo-controlled study. Br J Nutr, 2009; 101: 1722-1726.

26. RERKSUPPAPHOL $S$, et al. Randomized controlled trial of probiotics to reduce common cold in schoolchildren. PediatrInt, 2012; 54: 682-687.

27. RíO ME, et al. The nutritional status change the effectiveness of a dietary supplement of lactic bacteria on the emerging of respiratory tract diseases in children. Arch Latinoam Nutr, 2002; 52: 29-34.

28. ROUJIAN L, et al. Genomic characterisation and epidemiology of 2019 novel coronavirus: implications for virus origins and receptor binding. doi, 2020: 10.1016 S0140-6736(20)30251-8.

29. SALMINEN S, et al. Interaction of probiotics and pathogens--benefits to human health? CurrOpinBiotechnol, 2010; 21: 157-167.

30. SANTAGATI M, et al. Colonization, safety, and tolerability study of the Streptococcus salivarius $24 S M B c$ nasal spray for its application in upper respiratory tract infections. Eur.J.Clin.Microbiol.Infect.Dis, 2015; 34: 2075-2080

31. SANZ JM, et al. Effect of Lactobacillus casei on the incidence of infectious conditions in children. NutrHosp, 2006; 21: 547-551.

32. SKOVBJERG S, et al. Spray bacteriotherapy decreases middle ear fluid in children with secretory otitis media. Arch Dis Child, 2009; 94: 92-98.

33. SMITH TJ, et al. R. Effect of Lactobacillus rhamnosus L.GG(R) and Bifidobacterium animalis ssp. lactis BB-12(R) on health-related quality of life in college students affected by upper respiratory infections. Br.J.Nutr, 2013; 109: 19992007. 
34. STJERNQUIST-DESATNIK A, et al. Persistence of Lactobacillus plantarum DSM 9843 on human tonsillar surface after oral administration in fermented oatmeal gruel. A pilot study. ActaOtolaryngol.Suppl, 2000; 543: 215-219.

35. SWANLJUNG E, et al. Lactobacillus rhamnosus GG in adenoid tissue: Double-blind, placebo-controlled, randomized clinical trial. ActaOtolaryngol, 2015; 135: 824-830.

36. TAPIOVAARA L, et al. Lactobacillus rhamnosus GG in the middle ear after randomized, double-blind, placebocontrolled oral administration.Int.J.Pediatr.Otorhinolaryngol, 2014; 78: 1637-1641.

37. WONG SS, et al. Inhibition of Streptococcus pneumoniae adherence to human epithelial cells in vitro by the probiotic Lactobacillus rhamnosus GG. BMC Res.Notes, 2013; 6: 135.

38. WORLD HEALTH ORGANIZATION. Statement on the second meeting of the International Health Regulations (2005) Emergency Committee regarding the outbreak of novel coronavirus (2019-nCoV), 2020

39. WU D, et al. The SARS-CoV-2 outbreak: what we know. Int J Infect Dis, 2020; Mar 11. doi:10.1016/j.ijid.2020.03.004.

40. YANG Y, et al. Antiviral Effects of a Probiotic Metabolic Products against Transmissible Gastroenteritis Coronavirus. J Prob Health, 2017; 5: 184. doi:10.4172/2329-8901.1000184 